\title{
PENGGUNAAN BAHASA MANDARIN SEBAGAI MEDIUM DAKWAH DALAM NGO DI MALAYSIA
}

\author{
Aemy Elyani Mat Zain, Nur Aisyah Abu Hassan, \\ Safinah Ismali, Siti Zahidah Mu'al \\ Kolej Universiti Islam Antarabangsa Selangor (KUIS), \\ aemyelyani@kuis.edu.my \\ nuraisyah@kuis.edu.my \\ safinah@kuis.edu.my \\ sitizahidahmual@gmail.com
}

Diterima 25-03-2020 | Direview 27-05-2020 | Diterbitkan 30-06-2020

\begin{abstract}
The use of Mandarin language in Dakwah is remotely practiced by Malaysians. This is because majority of Malaysians especially Muslims are more comfortable using their native language which is Malay language and English as communication language used with mad'u from various backgrounds of religion and language. In fact, there are some more likey to practice dakwah and islah amongs only Muslims. Thus, this study is about a few dakwah movements in Malaysia that using Mandarin as communication language in dakwah movements. The research methodology used is qualitative from documented or written sourceS. The findings show that Mandarin language is an appropriate and relevant medium in dakwah communication because the number of Chinese people in Malaysia is also more than the Indians. The implication of the study found that there are two aspects the using of Mandarin language in Dakwah which are as preparation to preacher or daie to deal with Chinese mad'u; Mandarin as a dakwah communication language in facing Chinese mad'u through their organized activities and programs.
\end{abstract}

Keywords: The use of, Mandarin Language, NGO Malaysia

\begin{abstract}
Abstrak
Penggunaan bahasa Mandarin dalam dakwah begitu terpencil dipraktikkan oleh rakyat Malaysia. Ini kerana majoriti rakyat Malaysia khususnya umat Islam lebih selesa menggunakan bahasa ibunda iaitu bahasa Melayu dan bahasa Inggeris sebagai bahasa komunikasi dengan mad'u dari pelbagai latar belakang agama dan bahasa. Bahkan ada sebahagian pula, lebih cenderung menjalankan dakwah dan islah sesama muslim sahaja. Maka, kajian ini meneliti beberapa gerakan dakwah di Malaysia yang menjadikan bahasa Mandarin sebagai bahasa
\end{abstract}


komunikasi dakwah dalam gerakan tersebut. Metodologi kajian adalah kualitatif daripada bahan-bahan bertulis. Hasil kajian mendapati bahawa bahasa Mandarin sesuai dan relevan dijadikan bahasa komunikasi dakwah kerana bilangan orang Cina di Malaysia juga ramai berbanding orang India. Implikasi kajian mendapati bahawa terdapat dua aspek penggunaan bahasa Mandarin dalam dakwah iaitu sebagai persediaan kepada pendakwah atau daie untuk berhadapan dengan mad'u Cina; bahasa Mandarin sebagai bahasa komunikasi dakwah dalam menghadapi mad'u Cina melalui aktiviti dan program anjuran mereka.

Kata kunci: Penggunaan, Bahasa Mandarin, Dakwah, NGO, Malaysia

\section{Pendahuluan}

Jumlah penduduk Malaysia pada tahun 2018 diperkirakan mencapai 32,4 juta jiwa yang secara bertahap mengalami peningkatan tingkat pertumbuhannya (Departemen Statistik Malaysia; Kependudukan dan Demografi). Peningkatan ini sekaligus membuktikan bahwa salah satu ciri penduduk Malaysia adalah memiliki masyarakat yang beragam. Keragaman ini dapat dilihat dari segi suku, agama, bahasa bahkan budaya. Dilihat dari kelompok etnis di Malaysia tahun 2018, etnis Bumiputera mencapai persentase tertinggi di Malaysia sebesar 69,1\% (20,07 juta), sedangkan posisi tertinggi kedua adalah etnis Tionghoa sebesar 23,0\% (6,69 juta) dan sisanya dari etnis India dan lainnya. ${ }^{1}$

Keberagaman alam yang dimiliki Malaysia menjadikan pengelolaan dakwah juga dinamis. Di antara pengelolaan dakwah yang menjadi perhatian adalah penggunaan bahasa Mandarin sebagai salah satu platform dakwah. Hal ini dapat dikaitkan dengan adanya populasi Tionghoa Malaysia yang lebih besar setelah populasi Bumiputera sendiri. Salah satu bahasa komunikasi utama yang digunakan oleh penduduk Tionghoa Malaysia adalah Mandarin. Berkaitan dengan hal tersebut, terdapat beberapa gerakan dakwah yang aktif melakukan dakwah menggunakan bahasa Mandarin sebagai media komunikasi atau bahasa komunikasinya dengan mad'u.

Penelitian pendahuluan dilakukan terhadap beberapa gerakan dakwah di Malaysia yang menjadikan bahasa Mandarin sebagai bahasa komunikasi

\footnotetext{
1 “Jabatan Perangkaan Malaysia (Statistik: Penduduk \& Demografi).," accessed February 24, 2019, https://www.dosm.gov.my/v1/index.php?r=column/cthemeByCat\&cat=155\&bul_id= c1pqTnFjb29HSnNYNUpiTmNWZHArdz09\&menu_id=LOpheU43NWJwRWVSZkIWdzQ4 TlhUUT09.
} 
dakwahnya adalah Pembentukan Asosiasi Muslim Cina Malaysia (MACMA), Malaysian Islamic Welfare Organization (PERKIM), Hidayah Centre (HC), Yayasan Dakwah Islamiah Malaysia (YADIM) dan Multiracial Reverted Muslim (MRM).

\section{Metode}

Metode penelitian ini menggunakan kualitatif. Data kualitatif yang terlibat seperti data tertulis; Kajian ilmiah, artikel jurnal dan artikel, skripsi, website dan bahkan laporan surat kabar yang membahas tema-tema dalam makalah ini.

\section{Malaysian Chinese Muslim Association (MACMA)}

Berdirinya Malaysian Chinese Muslim Association (MACMA) merupakan titik awal semakin banyaknya orang Tionghoa yang dari hari ke hari memilih menjadi Muslim. Para profesional Muslim Tionghoa menyadari meningkatnya jumlah Muslim Tionghoa yang mengambil inisiatif dengan mendirikan Pendirian Asosiasi Muslim Tionghoa Malaysia (MACMA). Organisasi ini terdaftar pada tanggal 8 September 1994 dengan persetujuan dan dukungan dari YB Dato 'Dr. Abdul Hamid Othman, Menteri di Departemen Perdana Menteri. Visi yang ditetapkan oleh MACMA adalah "Berpartisipasi dan berkontribusi terhadap pembentukan Khairul Ummah atau The Best of Nations" (Siti Rohana Jasni dan Nor Fatin Azwa Mohd Shukri, 2018).

Asosiasi Muslim Tionghoa Malaysia (MACMA) telah menyelenggarakan berbagai program dakwah untuk mengajak masyarakat, khususnya masyarakat Tionghoa, untuk mendekati Islam. Di antara program dakwah yang diselenggarakan adalah buka puasa bersama komunitas nonMuslim, Tahun Baru Imlek dan Festival Lampion. Ketiga program tersebut merupakan program tahunan MACMA dan setiap tahun mereka menerima tanggapan yang menggembirakan. Keunikan program-program yang diselenggarakan oleh MACMA ini adalah melibatkan semua komunitas tanpa memandang keyakinan politik, keyakinan agama, dan budaya. Mereka memprioritaskan tujuan perkumpulan yaitu mempersatukan masyarakat sekaligus mengajak masuk Islam.

Program buka puasa bersama non muslim biasanya dilakukan bersama dengan pendampingan dan pendampingan yayasan lainnya. Para pemuka agama dari agama lain juga diajak berbuka puasa bersama komunitas Muslim Tionghoa dan mereka yang belum masuk Islam. Makanan dibagikan tanpa pertengkaran dan permusuhan. Proses bertukar pendapat dan berbagi 
pengalaman terkait amalan dan adat istiadat agama masing-masing dapat terlaksana dengan lancer. ${ }^{2}$

Selanjutnya, MACMA mengadakan berbagai kelas untuk kebaikan masyarakat. Diantaranya adalah kelas menjahit, kelas bahasa Mandarin, kelas Al-Quran dan kelas pencak silat. Kelas menjahit diluncurkan pada 16 Desember 2015. Kelas menjahit pertama juga diselenggarakan di hari yang sama. Jadwal kelas menjahit mulai 16 Desember 2015 setiap hari Rabu dan Kamis, mulai pukul 10.00 hingga 12.00. Mulai 1 Desember 2017, kelas menjahit diadakan setiap hari Senin dan Rabu, mulai pukul 09.00 hingga 12.00. Durasi satu kelas selama 3 jam. Kelas terbuka untuk umum, baik anggota maupun non-anggota MACMA. Biaya pendaftaran RM30 dan biaya RM10 untuk setiap kehadiran kelas.

Kelas bahasa Mandarin juga dilakukan di MACMA. Acara ini diadakan setiap hari Jumat dari jam 15.00 sampai 17.00. Mulai 1 Desember 2017, kelas diadakan dua kali seminggu pada hari Jumat dan Sabtu, mulai pukul 15.30 hingga 17.00. Tempat terbatas dan terbuka hanya untuk 15 siswa pertama, baik anggota maupun non-anggota MACMA. Biaya pendaftaran RM50 (kehadiran sekali seminggu) atau biaya bulanan RM80 (kehadiran dua kali seminggu). Kelas bahasa Mandarin ini menggunakan modul yang diberikan oleh Nur Farah Ain Leong. Modul ini dibagi menjadi tiga jenis modul yaitu Mengenal Dasardasar Pidato Bahasa Mandarin, Pidato Dasar Bahasa Mandarin Tingkat (1) dan Pidato Dasar Bahasa Mandarin Tingkat (2).

Selain itu, MACMA juga menerbitkan materi cetak seperti buletin dan pamflet tentang Islam dalam tiga bahasa, yaitu Bahasa Malaysia, Inggris dan Mandarin. Penerbitan materi dapat memudahkan penyampaian informasi ke berbagai kalangan. Penerbitan buletin dan pamflet ini bertujuan untuk menambah pengetahuan masyarakat Muslim Tionghoa. MACMA juga mengadakan dialog atau interaksi dengan organisasi Tionghoa melalui mata kuliah Filsafat Tiongkok Klasik, Konfusius, Tai Ji atau Chi Kung, etika, moral dan sebagainya. ${ }^{3}$ Cara ini bisa digunakan lebih efektif jika digunakan untuk berdakwah kepada komunitas profesional. Selanjutnya, salah satu kelas yang diadakan oleh MACMA adalah kelas Alquran. Kelas ini diadakan setiap hari

\footnotetext{
2 Wahab Muhammad Syahir, Ahmad Aakif Mohd Nor, and Taufiq Aspal, "Penggunaan Bahasa Mandarin dalam Dakwah oleh MACMA" (Malaysia, Jabatan Dakwah dan Usuluddin Fakulti Pengajian dan Peradaban Islam KUIS, 2018).

3 Abd Aziz Mohd Zain et al., Dakwah Islam di Malaysia. (Kuala Lumpur: Penerbit Universiti Malaya, 2006).
} 
Jumat dari jam 3 sore sampai jam 5 sore, atau waktu yang sesuai untuk siswa. Untuk kelas ini siswa diberi kebebasan untuk mengatur jadwal sendiri.

MACMA juga berkomitmen untuk terus melakukan diversifikasi program dalam berbagai bahasa lisan dan bahasa penyampaian. Komitmen ini membuat program MACMA menarik bagi orang Cina. Biasanya ada tiga jenis bahasa yang digunakan oleh MACMA sesuai dengan target audiensnya seperti Mandarin, Bahasa Malaysia dan Inggris. Perbedaan bahasa ini sangat erat kaitannya dengan daerah tempat tinggal dan latar belakang pendidikan. MACMA juga konsisten menyelenggarakan seminar, forum dan workshop yang membahas isu-isu terkini terkait ekonomi, agama, hukum dan lain-lain. Ini bertujuan untuk memberikan paparan kepada Muslim Tionghoa dan menginformasikan hak-hak mereka yang dijamin oleh Konstitusi Malaysia sebagai warga negara. ${ }^{4}$

\section{Pertubuhan Kebajikan Islam (PERKIM) / MalaysiaOrganisasi Kesejahteraan Islam Malaysia}

Pertubuhan Kebajikan Islam Islam Malaysia (PERKIM) didirikan pada tahun 1960 oleh Perdana Menteri pertama Malaysia, YAB Tunku Abdul Rahman Putra Al-Haj. Selain itu, Haji Ibrahim Ma Tian Yin juga merupakan tokoh penting dalam pendirian PERKIM bersama Tunku Abdul Rahman. ${ }^{5}$ Di antara tujuan awal didirikannya PERKIM adalah untuk memperluas dakwah Islam kepada non-Muslim dan membantu mualaf baru untuk mempelajari, menghargai dan mengamalkan ajaran Islam dalam kehidupan sehari-hari. Ini juga memberikan perlindungan dan siap membantu menyelesaikan setiap kesulitan yang dihadapi kerabat baru baik karena sakit atau masalah keluarga karena memeluk Islam. Tidak terbatas pada upaya dakwah, PERKIM juga menekankan pada unsur pendidikan dan kesejahteraan yang menyediakan, menyelenggarakan dan mengelola serta menyelenggarakan kelas pendidikan agama Islam melalui media dan metode lainnya. Belakangan, dengan diangkatnya sebagian keturunan Tionghoa-Muslim Hui menjadi PERKIM, PERKIM secara resmi menjadi santo pelindung Chinese-Muslim Association

\footnotetext{
${ }^{4}$ Mohd Faridh Hafez Mhd Omar and Sharifah Hayaati Syed Ismail Al-Qudsy, "Mohd Faridh Hafez Mhd Omar, Sharifah Hayaati Syed Ismail al-Qudsy. (2016). Sumbangan Organisasi CinaMuslim Dalam Keharmonian Beragama Di Malaysia: Tinjauan Terhadap Peranan Dan Cabaran PERKIM Dan MACMA” (International Da'wah Conference On Minority Group (Id-Com'16) Academy Of Islamic Studies University Of Malaya., University of Malaya, 2016).

${ }^{5}$ Engku Ahmad Zaki, Engku Alwi, and Yunus Abdullah Ma Zhengbin, Dakwah Multi Etnik: Gerakan Dakwah Islam Di Kalangan Masyarakat Cina Terengganu (Bangi: Universiti Kebangsaan Malaysia, 2010).
} 
of Malaysia (MACMA), dan bertanggung jawab menjadi pusat dakwah yang aktif menyebarkan ajaran Islam kepada masyarakat Tionghoa. ${ }^{6}$

Diantara upaya yang dilakukan oleh PERKIM untuk lebih meningkatkan efektifitas dakwah kepada mualaf, khususnya yang berbahasa Mandarin adalah dengan menyelenggarakan program yang disebut Program Syura untuk Penceramah Saudara Muslim Tionghoa. Menurut informasi yang diperoleh dari situs PERKIM, program tersebut diadakan untuk mengumpulkan para penceramah Muslim Tionghoa dari seluruh Malaysia untuk membahas metode dakwah efektif yang akan dimobilisasi oleh mereka di negara bagian masing-masing. Program ini menjadi tempat berkembang biak ide dan pemikiran para da'i untuk menciptakan koordinasi dalam kerja dakwah yang lebih efektif sejalan dengan misi program yaitu mengenalkan Islam sebagai agama yang sempurna kepada masyarakat Tionghoa di Malaysia secara efektif dengan pencapaian Islamisasi 30 persen pada tahun $2030 .^{7}$

Berikutnya adalah Program Pemurnian Ikhwanul Muslimin Cina. Program ini memberikan pelatihan teori dan praktik tentang keyakinan dan doa kepada peserta serta praktik kehidupan Islam sehari-hari. Bahasa yang digunakan dalam program ini tidak hanya bahasa Mandarin tetapi juga bahasa Kanton dan Hokkien. Hal ini dikarenakan penggunaan bahasa merupakan alternatif terbaik untuk melancarkan komunikasi menyampaikan ilmu sesuai dengan sasaran dakwah. Program ini juga merupakan salah satu inisiatif untuk menghasilkan saudara muslim yang sholeh sekaligus memperkuat atau memperkuat minat peserta dalam mencari ilmu agama. ${ }^{8}$

Sementara dari sisi pendidikan, PERKIM telah menunjukkan upaya yang kuat dengan menyediakan kelas belajar harian dan pusat pelatihan untuk saydata baru seperti Muslim Tionghoa seperti pembangunan PERKIM Islamic Da'wah Institute (IDIP) di Pangkalan Chepa, Kelantan. ${ }^{9}$

\section{Yayasan Dakwah Islamiyah Malaysia (YADIM)}

Yayasan Dakwah Islamiah Malaysia (YADIM) didirikan pada tahun 1974 oleh pemerintah Malaysia. Gagasan mendirikan Yayasan Dakwah melalui

\footnotetext{
${ }^{6}$ Siti Rohani Jasni and Nor Fatin Azwa Mohd Shukri, "Penggunaan Bahasa Mandarin Dalam Gerakan-Gerakan Dakwah Di Malaysia.” (Malaysia, Kajang: Jabatan Dakwah dan Usuluddin, Fakulti Pengajian Peradaban Islam Kolej Universiti Islam Antarabangsa Selangor., 2018).

${ }^{7}$ Rohani Jasni and Mohd Shukri.

${ }^{8}$ Rohani Jasni and Mohd Shukri.

${ }^{9}$ Mhd Omar and Syed Ismail Al-Qudsy, "Mohd Faridh Hafez Mhd Omar, Sharifah Hayaati Syed Ismail al-Qudsy. (2016). Sumbangan Organisasi Cina-Muslim Dalam Keharmonian Beragama Di Malaysia: Tinjauan Terhadap Peranan Dan Cabaran PERKIM Dan MACMA.”
} 
upaya Perdana Menteri YAB Malaysia, Tun Haji Abdul Razak Hussein untuk membentuk Badan Koordinasi Gerakan Dakwah berdasarkan kebutuhan masyarakat. Ini telah menerima tanggapan yang menggembirakan di antara komunitas Muslim sejak awal 70-an. Keberadaannya juga atas desakan masyarakat tahun itu. YADIM sebagai Badan Perwalian yang terdaftar di bawah "Trust Incorporation Ordinance 1952" bertanggung jawab langsung kepada YAB. Perdana Menteri Malaysia. Undang-undang ini sebenarnya bernama Undang-undang Pengawas (Pendirian) 1952 atau Ordonansi Pengawas (Korporasi) 1952 (No.73 tahun 1952) yang disetujui oleh Jaksa Agung Tan Sri Abdul Kadir Yusof pada tanggal 30 Mei 1974. Undang-undang ini kemudian diubah pada 1 Januari $2006 .{ }^{10}$

Sejarah berdirinya YADIM diawali dengan pemaparan makalah dalam Seminar ke-2 Kongres Ekonomi Islam yang dilaksanakan pada tanggal 7-9 April 1972 di Petaling Jaya yang diselenggarakan oleh Kementerian Pembangunan Nasional dan Pedesaan. Kongres ini telah dirumuskan untuk mendirikan sebuah yayasan bernama Islamic Spreading Foundation. Total ada enam yang dihadirkan dalam kongres ini, di antaranya adalah "Pendirian Korporasi Keuangan Muslim (Baitul Mal Pusat)" yang dibawakan oleh Tuan Haji Nik Mohd Mohyideen Musa. Juga dalam kompilasi makalah ini adalah En. Nakhaie Bin Ahmad yang saat itu menjabat sebagai Sekretaris Makalah. ${ }^{11}$ Berbagai upaya dakwah telah dilakukan YADIM kepada masyarakat. Berdasarkan misi YADIM yaitu melaksanakan dan mengkoordinir kegiatan dakwah lintas ideologi dan metodologi. Visinya adalah memimpin bisnis dakwah berdasarkan Alquran dan Hadits sehingga YADIM akan terus berupaya menjadi penggerak yang efektif dalam memanfaatkan potensi umat melalui pendekatan dakwah Islam dan dakwah Islam. ${ }^{12}$

YADIM juga terlibat dalam program yang berkaitan dengan mualaf Cina di Malaysia, termasuk di Kelantan. Yayasan Dakwah Islamiah Malaysia (YADIM) akan membantu mualaf dari Malaysian Chinese Muslim Association (MACMA) termasuk mengadakan program pengabdian masyarakat Siam dan Tionghoa di negara bagian tersebut. Menurut Mahadi Awang, Kontribusi Ketua Pelaksana YADIM Kawasan Timur dalam bentuk uang juga akan

\footnotetext{
${ }^{10}$ Masitah Esa, Amini Amir Abdullah, and Siti Suhaila Ihwani, "Metodologi Dakwah Yayasan Dakwah Islamiah Malaysia.," Tinta Artikulasi Membina Ummah 3 No.2 (2017): 26-37.

${ }^{11}$ Rohani Jasni and Mohd Shukri, "Penggunaan Bahasa Mandarin Dalam Gerakan-Gerakan Dakwah Di Malaysia."

${ }^{12}$ Esa, Abdullah, and Ihwani, "Metodologi Dakwah Yayasan Dakwah Islamiah Malaysia."
} 
diberikan untuk menggerakkan program yang direncanakan untuk tahun ini dan yang akan datang. Program yang direncanakan dalam waktu dekat ini adalah Workshop Doa dan Menyembelih Hewan di kantor MACMA Kelantan. Akan mendatangkan 25 Young Dakwah Fellows dari jurusan ini yaitu lulusan luar dan dalam negeri yang dilatih khusus oleh YADIM untuk membimbing anggota MACMA, bahkan akan mensponsori semua biaya dalam workshop ini. $^{13}$

Diantara kegiatan atau program yang dilakukan YADIM adalah Program Perayaan Tahun Baru Imlek. Program ini tidak hanya untuk merayakan tahun baru Imlek tetapi merupakan salah satu upaya dakwah yang dilakukan oleh YADIM untuk lebih dekat atau bergaul dengan saudara-saudara baru Tionghoa bahkan mereka yang belum masuk Islam pun tertarik untuk mengikuti program tersebut untuk menyampaikan dakwahnya. Program ini dilaksanakan di masjid-masjid serta melaksanakan shalat berjamaah dengan saudara-saudara Tionghoa baru di sana. Berikutnya adalah Program Penguatan Iman. Program ini diadakan dengan tujuan untuk memberikan pemaparan tentang keimanan Islam kepada para peserta agar mereka memahami konsep keimanan dengan benar. Di antara yang disinggung, di antaranya pengenalan sholat dan riwayat wajib beribadah, juga disinggung tentang hikmah beribadah yang perlu dilakukan bagi seorang muslim. Program ini tidak hanya terbuka untuk mualaf tetapi juga bagi yang belum memeluk agama Islam namun ingin mengenal Islam sangat disambut baik oleh YADIM untuk berpartisipasi. ${ }^{14}$

\section{Hidayah Centre}

Hidayah Centre (HC) didirikan pada tahun 2005 sebagai lembaga yang berfungsi untuk membangun hubungan antara berbagai komunitas yang berbeda suku dan latar belakang agama di Malaysia. Ini juga menjadi pusat dukungan bagi kerabat baru yang membutuhkan pembinaan dalam berbagai aspek dan juga membutuhkan tempat tinggal sementara.

Pada tanggal 29 Februari 2012, Hidayah Centre secara resmi terdaftar di bawah Biro Hukum di Departemen Perdana Menteri sebagai Yayasan Hidayah Centre. Visi yang diemban oleh Hidayah Centre Foundation menjadi badan pemerintahan yang unggul dalam 'penjangkauan' dan dukungan kerabat baru. Sedangkan misi yang ingin dicapai Hidayah Centre adalah membagikan dakwah Islam universal kepada semua lapisan masyarakat, mengoreksi kesalahpahaman tentang Islam dan juga memberikan dukungan kepada

\footnotetext{
${ }^{13}$ Esa, Abdullah, and Ihwani.

${ }^{14}$ Esa, Abdullah, and Ihwani.
} 
saudara-saudara baru sebagai tanggung jawab kemanusiaan. Hidayah Centre Foundation berupaya untuk mencapai misi tersebut dengan menjalin hubungan baik, memimpin dan mendampingi individu muslim dan ormas Islam dalam upaya memberdayakan upaya serupa di Malaysia dan kawasan Asia Pasifik . ${ }^{15}$

Di antara program yang diselenggarakan oleh Hidayah Centre untuk menarik non-Muslim mendekati Islam adalah open house Tahun Baru Imlek. Open house ini merupakan acara tahunan yang diadakan untuk merayakan kerabat baru dan juga mengajak masyarakat sekitar untuk berpartisipasi di dalamnya guna membina hubungan baik dengan etnis ini. Selain itu, programjuga digelar open day Masjid. Hari buka masjid dikenal dengan program "musholla", yaitu tur masjid yang sering dilakukan di masjid seksi 7 di Shah Alam. Program ini memberikan kesempatan kepada non muslim untuk belajar lebih banyak tentang Islam dan juga memberikan kesempatan kepada sesama relawan Hidayah Centre untuk membimbing dan memberikan informasi kepada non muslim selama berkeliling masjid tentang teori dan praktek seperti sholat, membaca Alquran dan prinsip-prinsip Islam. Program ini diterima dengan baik oleh komunitas non-Muslim. ${ }^{16}$

Kemudian juga diadakan kelas dakwah bagi non muslim. Kelas diadakan seminggu sekali pada hari Minggu, mulai dari jam 09.00 sampai jam 12.00 siang. Kelas ini diklasifikasikan menurut tingkat pemahaman kerabat baru dalam menerima dan memahami Islam. Selain memberikan kelas, kerabat baru juga menerima tunjangan setiap mengikuti kelas. Ini untuk membantu mereka menjalani kehidupan baru setelah memeluk Islam. Mereka mendapat bantuan berupa perlindungan, finansial untuk mendorong mereka terus mendalami Islam setelah diusir dari keluarga dan sebagainya. ${ }^{17}$

Selain kegiatan sosialisasi, Hidayah Centre juga terlibat dalam pembentukan daie atau relawan yang tertarik menyumbangkan tenaga dalam gerakan dakwah ini. Berbagai pelatihan dan kursus dakwah diberikan kepada daie dan relawan agar lebih siap menghadapi tantangan dakwah di luar sana. Diantara pelatihan atau kursus yang ditawarkan adalah Dakwah Dalam Masyarakat Majmuk (DDMM). DDMM adalah kursus lengkap yang ditawarkan kepada semua orang Malaysia yang mencakup 6 fase yang berisi pengetahuan

\footnotetext{
15 Nor Hanizah Mat Harizan and Nur Fatihah Syahirah Nor Sukeri, "Penggunaan Bahasa Mandarin Dalam Dakwah Hidayah Centre" (Jabatan Dakwah dan Usuluddin, Fakulti Pengajian Peradaban Islam KUIS., 2018).

${ }^{16}$ Mat Harizan and Nor Sukeri.

${ }^{17}$ Mat Harizan and Nor Sukeri.
} 
dakwah untuk non- Muslim. Selain DDMM, ada juga Training of Trainers (TOT) yang ditawarkan kepada siapa saja yang pernah melalui DDMM. Latihan ini untuk menghasilkan daie yang dapat menjadi pembicara DDMM. Di bawah unit pelatihan juga ada klub relawan, Rakan Hidayah. Mitra Hidayah didirikan untuk membantu Hidayah Centre untuk setiap kegiatan atau program yang dilakukan oleh Hidayah Centre. Anggotanya berasal dari kalangan Muslim dan kerabat baru. ${ }^{18}$

Hidayah Centre juga mengadakan kelas bahasa Mandarin yang dimulai pada tahun 2018 untuk tingkat dasar sebagai salah satu pemaparan kepada relawan di bawah Hidayah Centre. Kelas ini memberikan kesempatan kepada relawan yang terdiri dari umat Islam dan kerabat baru untuk mempelajari dasardasar belajar bahasa Mandarin dan kalimat yang dapat digunakan untuk memulai percakapan. Hal tersebut merupakan salah satu upaya untuk meningkatkan keterampilan dakwah para relawan dengan penambahan pendekatan dakwah yang dilakukan oleh Hidayah Centre. ${ }^{19}$

\section{Malaysia Reverted Muslim (MRM)}

Malaysia Reverted Muslim (MRM) didirikan oleh Firdaus Wong Wai Hung sebagai platform untuk berdakwah kepada komunitas non-Muslim serta memungkinkan mualaf untuk berinteraksi dan mendapatkan dukungan di Facebook. Halaman Facebook MRM telah berdiri sejak 2010. Pada awal berdirinya, MRM hanyalah sebuah platform di dunia maya tetapi semuanya berubah ketika pertemuan pertama kali diatur pada awal tahun 2011 di MACMA Ipoh (Malaysia Reverted Muslim Profile). Visi yang dibawa oleh MRM adalah untuk "menyampaikan pesan Islam yang sebenarnya kepada nonMuslim \& Muslim" dan misi mereka dalam mencapai visi tersebut adalah menjawab kesalahpahaman tentang Islam di kalangan non-Muslim dan nonMuslim, menciptakan kesadaran akan tanggung jawab setiap Muslim untuk menyampaikan Pesan Islami, melatih lebih banyak umat Islam untuk menyampaikan pesan Islam, memberikan platform bagi masyarakat untuk memperoleh informasi tentang Islam dan menciptakan sistem dukungan bagi umat Islam terutama di kalangan mualaf. ${ }^{20}$

\footnotetext{
${ }^{18}$ Nur Aisyah Abu Hasan, "Hidayah Centre Foundation: Bahu Sandaran Kepada Saudara Baru" (Persidangan Antarabangsa Tokoh Ulama Melayu Nusantara, Malaysia, Kolej Universiti Islam Antarabangsa Selangor (KUIS), 2017).

${ }^{19}$ Abu Hasan.

${ }^{20}$ Anon, "Profil Malaysia Reverted Muslim (MRM)" (Kuala Lumpur, Program Pembangunan Usaha Da’wah \& Kebajikan, 2013).
} 
Pendekatan yang digunakan oleh Malaysia Reverted Muslim adalah untuk mempersiapkan anggota dan relawan kami dengan pengetahuan Islam untuk menyampaikan pesan Islam kepada masyarakat. Selain itu, anggota kami juga dikirim ke kursus atau seminar untuk meningkatkan ilmu guna memudahkan upaya dakwah. MRM bukanlah LSM yang bersaing dengan LSM Islam lainnya tetapi keberadaan MRM adalah untuk saling melengkapi. Selain itu, MRM akan berupaya untuk meningkatkan efektifitas dakwah yang telah dilakukan dengan mengeksplorasi metode-metode terkini untuk mendobrak hambatan dakwah Islam agar dakwah Islam dapat tersampaikan ke berbagai lapisan masyarakat. ${ }^{21}$

Selain itu, MRM juga membuat konsep yaitu menghadirkan masjid kepada masyarakat karena banyak program keislaman yang dilakukan di dalam masjid sementara banyak kelompok sasaran berada di luar masjid. Kita perlu menyeimbangkan program di dalam \& di luar masjid agar menjangkau berbagai lapisan masyarakat. Selain itu, MRM juga terlibat dalam pembinaan mualaf yang haus ilmu dan juga tidak dilupakan oleh saudara muslim lainnya. Kami juga membuat sistem muakhat yang diambil bersamaan dengan acara 'muakhat' yang merupakan ikatan persaudaraan yang dijalin oleh Rasulullah SAW antara para sahabat Muhajirin \& Ansar di Madinah. ${ }^{22}$

Di antara program atau kegiatan dakwah yang dilakukan oleh MRM adalah dakwah jalanan atau dakwah jalanan merupakan program berkala yang dilakukan oleh relawan MRM dari waktu ke waktu. Berbekal hadits yang diriwayatkan Bukhari Sampaikan dari saya bahkan satu ayat, para relawan akan turun jalan untuk menyampaikan dakwah Islam kepada masyarakat. Fokus MRM adalah mereka yang belum beragama Islam dan juga Muslim yang tidak menjalankan cara hidup Islami. MRM juga sering diundang oleh Institusi Pendidikan, Instansi Pemerintah, Badan Usaha dan LSM lainnya untuk program penguatan iman melalui perbandingan agama. Selain itu, MRM juga sering diundang untuk program motivasi khususnya bagi remaja yang sedang mencari jati diri di usia tersebut. MRM juga memaksimalkan kemajuan teknologi untuk menyampaikan Islam kepada Muslim dengan tetap menggunakan bahasa dialek selain bahasa Inggris. Sejauh ini, video dakwah dalam bahasa Kanton, Iban bahkan dialek Hokkien telah diunggah di youtube dan mendapat respon yang menggembirakan dari komunitas non-Muslim. ${ }^{23}$

\footnotetext{
${ }^{21}$ Anon.

22 Anon.

23 Anon.
} 
MRM juga melakukan segala upaya untuk memfasilitasi individu yang tertarik memeluk Islam untuk melakukannya. Setiap individu yang berminat maka MRM akan langsung mengislamkan mereka sambil menunggu upacara resmi atau dibawa ke Departemen Agama untuk proses pendaftaran karena yang terpenting islamisasinya sah di sisi Allah SWT. MRM biasa melakukan Islamisasi melalui telepon dan terkadang pada pukul 2 atau 3 pagi. ${ }^{24}$

Berikutnya adalah pembangunan kuil Muslim. Salah satu tugas dan tanggung jawab pihak-pihak tertentu di MRM adalah untuk memudahkan mualaf untuk mencari jodoh dan terkadang MRM juga akan memperkenalkan mereka kepada pasangan yang cocok dan terserah mereka untuk melanjutkan hubungan ini ke tingkat yang lebih serius. MRM selalu siap membantu dalam hal keuangan, keahlian bahkan waktu untuk memungkinkan mereka membangun rumah tangga yang diinginkan. ${ }^{25}$

MRM juga mengadakan kelas fardhu ain dan konseling. MRM mengadakan kelas fardhu ain untuk mualaf di sekitar Lembah Klang di Serdang, Bangi, Kepong, Petaling Jaya dan juga melalui kerjasama dengan LSM lain seperti MACMA Selangor dan MACMA Ipoh. Meskipun merupakan kelas fardhu ain untuk mualaf, namun kelas ini juga terbuka bagi mereka yang terlahir beragama Islam dan mereka yang bukan muslim yang tertarik untuk mempelajari Islam lebih dalam. Semua kelas yang diadakan oleh MRM tidak dipungut biaya. MRM juga memberikan bantuan perumahan untuk anak yatim piatu yaitu Bait Al-Amin. Meski dakwah dan mualaf menjadi fokus utama MRM, namun yang kurang mampu tidak dilupakan, terutama kesejahteraan anak yatim piatu. MRM juga mengadakan program ziarah komunitas dan ziarah tunawisma, menyempurnakan kursus sholat saya yang bertujuan untuk memperbaiki dan memperbaiki dalam amalan sholat wajib, program bantuan Ramadhan juga diperpanjang, Reverts Gathering yang mengumpulkan para mualaf untuk membangun persaudaraan yang lebih kuat satu sama lain, program buka puasa. , memberikan cinderamata dakwah seperti kaos, notebook, bookmark, mug dan lain sebagainya, mengadakan kelas bahasa Mandarin, inggris, arab, multimedia (komputer, photoshop) terbuka untuk umum termasuk non muslim secara gratis untuk mendekatkan mereka dengan MRM dan lain sebagainya. membuka pintu dakwah untuk mereka dan berbagai program dan kegiatan dakwah menarik lainnya yang diadakan oleh MRM. ${ }^{26}$

\footnotetext{
24 Anon.

25 Anon.

26 Anon.
} 
MRM juga telah mengadakan beberapa kegiatan yang menitikberatkan pada kesadaran dakwah Islam ke berbagai lapisan masyarakat. Diantaranya dengan merilis video dakwah yang berkualitas. Fokus dari video dakwah ini adalah untuk menyampaikan pamflet dan ajaran kepada non muslim khususnya di Malaysia. Video dakwah ini berfokus pada migrasi pihak-pihak tertentu yang dapat berdampak pada masyarakat. Video dakwha yang lebih efektif dapat disajikan dengan berbagai macam penggunaan bahasa seperti Mandarin dan Inggris sehingga pencapaiannya lebih menarik dan meluas. ${ }^{27}$

\section{Simpulan}

Berdasarkan pembahasan di atas dapat ditarik kesimpulan:

1. Terlihat jelas bahwa pengelolaan dakwah menggunakan bahasa Mandarin oleh Pembentukan Asosiasi Muslim Cina Malaysia (MACMA), Malaysian Islamic Welfare Organization (PERKIM), Hidayah Center (HC), Yayasan Dakwah Islamiah Malaysia (YADIM) dan Multiracial Reverted Muslim (MRM) merupakan fenomena dakwah yang harus dicontoh oleh masyarakat Malaysia dalam mendekati mad'u.

2. Penggunaan bahasa Mandarin dilakukan secara berbeda sesuai dengan kesesuaian dan keahlian yang ada di gerakan dakwah. Penggunaan bahasa Mandarin dapat dilihat dari dua aspek. Pertama; dalam persiapan untuk daie dan pengkhotbah untuk berkomunikasi dengan mualaf Cina atau sebaliknya seperti kelas bahasa Mandarin. Kedua; sebagai bahasa komunikasi dakwah dengan mualaf Tionghoa atau Tionghoa non-Muslim dalam kegiatan dan program yang mereka selenggarakan seperti Program Purifikasi Ibadah Ikhwanul Muslimin Tionghoa.

3. Meskipun penggunaan bahasa Mandarin tampaknya masih baru di Malaysia, penting bahwa bahasa asing ini mendapat tempat karena sifat penduduk Malaysia yang jamak. Bahkan berkomunikasi dalam bahasa Mandarin oleh penduduk Tionghoa Malaysia merupakan kebiasaan dan rutin mereka karena sistem pendidikan formal mereka di Malaysia adalah Mandarin. Saran penulis untuk menyempurnakan penelitian ini adalah perlunya sesi wawancara purposive individu dalam gerakan ini yang

\footnotetext{
${ }^{27}$ Nurul Rabiatul Adawiah Binti Badurdin, Siti Nadhirah Binti Nordin, and Norazmina Binti Azman, "Multiracial Reverted Muslims. Kajang" (Malaysia, Jabatan Dakwah dan Usuluddin, Kolej Universiti Islam Antarangsa Selangor., 2017).
} 
langsung berdakwah dalam bahasa asing ini. Bahkan, menganalisis lebih lanjut bentuk program dan pendekatan yang mereka gunakan melalui penggunaan bahasa Man

\section{Daftar Pustaka}

Abu Hasan, Nur Aisyah. "Hidayah Centre Foundation: Bahu Sandaran Kepada Saudara Baru." Persidangan Antarabangsa Tokoh Ulama Melayu Nusantara, Kolej Universiti Islam Antarabangsa Selangor (KUIS), 2017.

Ahmad Zaki, Engku, Engku Alwi, and Yunus Abdullah Ma Zhengbin. Dakwah Multi Etnik: Gerakan Dakwah Islam Di Kalangan Masyarakat Cina Terengganu. Bangi: Universiti Kebangsaan Malaysia, 2010.

Anon. "Profil Malaysia Reverted Muslim (MRM)." Program Pembangunan Usaha Da'wah \& Kebajikan, 2013.

Binti Badurdin, Nurul Rabiatul Adawiah, Siti Nadhirah Binti Nordin, and Norazmina Binti Azman. "Multiracial Reverted Muslims. Kajang." Jabatan Dakwah dan Usuluddin, Kolej Universiti Islam Antarangsa Selangor., 2017.

Esa, Masitah, Amini Amir Abdullah, and Siti Suhaila Ihwani. "Metodologi Dakwah Yayasan Dakwah Islamiah Malaysia." Tinta Artikulasi Membina Ummah 3 No.2 (2017): 26-37.

"Jabatan Perangkaan Malaysia (Statistik: Penduduk \& Demografi)." Accessed February 24, 2019. https://www.dosm.gov.my/v1/index.php? $\mathrm{r}=$ column/cthemeByCat\&c at $=155 \&$ bul_id $=$ c1pqTnFib29HSnNYNUpiTmNWZHArdz09\&menu _id=L0pheU43NWJwRWVSZklWdzQ4TlhUUT09.

Mat Harizan, Nor Hanizah, and Nur Fatihah Syahirah Nor Sukeri. "Penggunaan Bahasa Mandarin Dalam Dakwah Hidayah Centre." Jabatan Dakwah dan Usuluddin, Fakulti Pengajian Peradaban Islam KUIS., 2018.

Mhd Omar, Mohd Faridh Hafez, and Sharifah Hayaati Syed Ismail Al-Qudsy. "Mohd Faridh Hafez Mhd Omar, Sharifah Hayaati Syed Ismail alQudsy. (2016). Sumbangan Organisasi Cina-Muslim Dalam Keharmonian Beragama Di Malaysia: Tinjauan Terhadap Peranan Dan Cabaran PERKIM Dan MACMA.” University of Malaya, 2016. 
Mohd Zain, Abd Aziz, Nor Raudah Hj Siren, Yusmini Md Yusoff, and et.al. Dakwah Islam di Malaysia. Kuala Lumpur: Penerbit Universiti Malaya, 2006.

Muhammad Syahir, Wahab, Ahmad Aakif Mohd Nor, and Taufiq Aspal. "Penggunaan Bahasa Mandarin dalam Dakwah oleh MACMA." Jabatan Dakwah dan Usuluddin Fakulti Pengajian dan Peradaban Islam KUIS, 2018.

Rohani Jasni, Siti, and Nor Fatin Azwa Mohd Shukri. "Penggunaan Bahasa Mandarin Dalam Gerakan-Gerakan Dakwah Di Malaysia." Kajang: Jabatan Dakwah dan Usuluddin, Fakulti Pengajian Peradaban Islam Kolej Universiti Islam Antarabangsa Selangor., 2018. 